\title{
Mártir de la justicia y de la opción por los pobres \\ Homilía en la misa del XXX aniversario del martirio de monseñor Óscar Arnulfo Romero, en la cripta de Catedral Metropolitana, 24 de marzo de 2010
}

\author{
† Samuel Ruiz García, \\ obispo emérito de San Cristóbal de las Casas, \\ Chiapas, México; \\ presidente honorario del SICSAL
}

\section{Saludo}

Queridos hermanos obispos.

Queridas hermanas y hermanos ministros, reverendos, sacerdotes, pastoras y pastores, religiosas y religiosos de las distintas Iglesias y congregaciones que nos acompañan esta tarde.

Queridas hermanas y hermanos solidarios, venidos desde todos los rincones del planeta.

Hermanas y hermanos salvadoreños que hoy nos acogen.

Es un inmerecido privilegio el que nos han concedido este día, al presidir esta eucaristía de conmemoración en el XXX aniversario de la Pascua martirial de monseñor Óscar Arnulfo Romero y Galdámez, inuestro querido monseñor!

Agradezco tal honor a las hermanas y hermanos de la Comunidad Óscar Arnulfo Romero de esta cripta de Catedral, a quienes desde ya reconozco esa inquebrantable voluntad que ha mantenido, en este preciso lugar, la memoria viva de Romero. ¡Gracias hermanas, muchas gracias! 
Gracias también a monseñor José Luis Escobar Alas, arzobispo de San Salvador, por su amable carta de invitación.

Saludo también a mis hermanas y hermanos del Servicio Internacional Cristiano de Solidaridad "Óscar Romero", el SICSAL, congregados estos días en nuestra asamblea internacional de grupos y comités de solidaridad, y que también están cumpliendo treinta años de compromiso con los pueblos de América Latina, junto a la CORCA y a CEIPES.

Hermanas y hermanos, contemplan mis ojos un acontecimiento realmente asombroso y sorprendente, pues, estando en una cripta, no descubro yo signos de muerte, sino de vida; no se revelan ante mí gestos de pesadumbre ni de apatía, sino de un dinamismo que transmite una energía poderosa que invade este recinto; no veo rostros de dolor y resignación sombría, sino miradas llenas de una profunda fe y esperanza que contagian...

No es la tumba de un hombre muerto - asesinado, diría con mayor precisión - la que desde aquí observamos, sino el faro luminoso que nos ha guiado durante las últimas tres décadas, en la búsqueda y en la construcción del Reino de Dios que nos vino a anunciar Jesús.

Es el mismo asombro que vivimos el Domingo de Ramos de hace treinta años, cuando, junto al cardenal Corripio Ahumada y monseñor Sergio Méndez Arceo, vinimos desde México para acompañar al pueblo salvadoreño en los funerales de monseñor Romero.

Ese Domingo de Ramos, que cobró la vida de decenas de hermanos que fueron brutalmente reprimidos y masacrados por las balas asesinas que venían desde las azoteas que rodean la plaza catedral. Gente sencilla del pueblo que, a pesar de la represión, venía a contemplar por última vez el rostro sereno de su pastor, y a reconocer lo que por ellos había hecho en sus cortos tres años como arzobispo de San Salvador.

Nos asombró ese día, como lo hace ahora, la plena convicción de que, con esos acontecimientos ignominiosos, no se apagaba una luz, sino que se encendía una hoguera que nos envuelve, que nos quema y que nos consume con pasión, y que nunca podrá ser apagada. Un fuego y una luz tan potentes, que han rebasado ya las fronteras y los mares que dividen a nuestros continentes.

La llama de Romero permanecerá encendida, mientras haya uno de nosotros que se comprometa a mantenerla viva, como lo hace esta comunidad de la cripta.

Hace treinta años, el mundo vivía una crisis caracterizada por la imposición de un sistema político y económico que, para subsistir, exigía el sacrificio de miles de mujeres y hombres, convirtiéndolas en víctimas inocentes de la avaricia y del egoísmo de unos cuantos. Sistema que, para operar sin "obstáculos" y sin "contratiempos", recurrió a la militarización y a la paramilitarización de una 
sociedad supuestamente democrática, abriendo así uno de los capítulos más tristes de nuestra historia reciente.

Todavía se conmueven nuestros corazones al recordar a aquellas madres que recorrían las cárceles y los hospitales en busca de sus hijos desaparecidos. Todavía nos indignamos al evocar esos cuerpos mutilados, arrojados a los basureros, devorados por los animales de rapiña.

Todavía nos duelen los más de setenta y cinco mil muertos de esa guerra que desangró al "Pulgarcito de América" y los miles de mártires de toda América Latina que derramaron su sangre en la defensa de los más elementales derechos humanos: el derecho a una vida digna, el derecho a la justicia, el derecho a la paz.

$\mathrm{Y}$ no es que tenga yo el afán de abrir heridas que poco a poco han ido cicatrizando, pero hoy mismo no podemos recordar a monseñor Romero fuera del contexto que, como hombre, como pastor y como obispo le tocó vivir; sería una falta a la memoria histórica del pueblo salvadoreño y latinoamericano, y un insulto a las familias de esas víctimas por las cuales él mismo ofrendó su vida.

\section{Universalidad de Romero}

Monseñor Romero sigue viviendo en su pueblo — tal como él mismo lo profetizó-, pero su presencia es un dato no solamente eclesial y episcopal, sino también sociológico; es un hecho cultural y político (en el amplio sentido de la palabra, y espero se entienda así), forma parte de la realidad de América Latina y, lo que es más sorprendente, forma parte del futuro de ella misma. Hay que contar con él para hacer la historia ya no solo de este querido pueblo de El Salvador, sino de todo el continente.

Quiero decir aquí algo que, espero, no ofenda a nuestras hermanas y hermanos salvadoreños, y lo digo con mucho cariño y gratitud: ustedes tuvieron la fortuna de convivir con monseñor Romero, el privilegio de sentirlo, de escucharlo; y lo tienen y lo cuidan aquí, en su Catedral... pero, desde hace tres décadas, monseñor Romero es un ser universal, pertenece a toda la humanidad, no es propiedad de un grupo o de una asociación; su palabra y su obra han rebasado todas las fronteras humanas. Dios mismo, al aceptar su sacrificio, nos lo ha dado como testimonio de esperanza y de liberación para todas las mujeres y hombres que luchan por esos mismos ideales, que, finalmente, están inspirados en el seguimiento y en el proseguimiento de Jesús en la construcción del Reino.

La vida, el pensamiento y la obra de monseñor Romero se han convertido en verdadero sacramento de unidad y de solidaridad entre los pueblos del mundo. ¡Por eso estamos aquí, para acompañarles, para agradecerles y para reconocer esa universalidad de monseñor! 
Recordemos cómo, desde el mismo 29 de marzo de 1980, un grupo de obispos latinoamericanos firmó un documento en el que se decía:

Tres cosas admiramos y agradecemos en el episcopado de monseñor Óscar Arnulfo Romero: fue, en primer lugar, anunciador de la fe y maestro de la verdad... fue, en segundo lugar, un acérrimo defensor de la justicia... en tercer lugar, fue el amigo, el hermano, el defensor de los pobres y oprimidos, de los campesinos, de los obreros, de los que viven en barrios marginales.

Mons. Romero ha sido un obispo ejemplar porque ha sido un obispo de los pobres en un continente que lleva tan cruelmente la marca de la pobreza de las grandes mayorías, se insertó entre ellos, defendió su causa y ha sufrido la misma suerte de ellos: la persecución y el martirio. Mons. Romero es el símbolo de toda una Iglesia y un continente, verdadero siervo doliente de Yahvé que carga con el pecado de injusticia y de muerte de nuestro continente.

No nos ha sorprendido su asesinato, pues no podía ser otro su destino si fue fiel a Jesús, y si se insertó de veras en el dolor de nuestros pueblos. Su muerte no es un hecho aislado, forma parte del testimonio de una Iglesia que en Medellín y Puebla optó, desde el Evangelio, por los pobres y oprimidos. Por eso ahora comprendemos mejor, desde el martirio de monseñor Romero, la muerte por hambre y enfermedad, realidad permanente en nuestros pueblos; así como los innumerables martirios, las innumerables cruces que jalonan nuestro continente en estos años: campesinos, pobladores, obreros, estudiantes, sacerdotes, agentes de pastoral, religiosas, obispos encarcelados, torturados, asesinados por creer en Jesucristo y amar a los pobres. Son como la muerte de Jesús: fruto de la injusticia de los hombres y a la vez semilla de la resurrección. (Comunicado firmado por varios obispos. San Salvador, 29 de marzo de 1980.)

Esa universalidad se la ha ganado no solo por mérito propio; se la ha otorgado la universalidad de las víctimas inocentes de las guerras, la universalidad de los empobrecidos de todos los lugares y de todas las épocas de la humanidad, la universalidad del pueblo de Dios que espera con fe el advenimiento de "un mundo nuevo y un cielo nuevo".

\section{Nuestra realidad}

Vivimos hoy, en el año 2010, el agravamiento de esa crisis heredada del siglo pasado, en una nueva época. El sistema económico y político impuesto por los poderosos, con sus ídolos del dinero, el lucro y la ganancia por delante, han excluido a más del setenta por ciento de la humanidad de los beneficios de la riqueza que es de todos. 
Miles de niños mueren cada año de hambre y de enfermedades curables; los jóvenes están siendo privados de una educación gratuita y liberadora, que les aleje de las redes fáciles del alcoholismo, de la drogadicción o de las pandillas o maras.

Los avances tecnológicos no redundan en bienestar, sino en el desempleo de millones de mujeres y hombres desesperados por no tener los recursos suficientes para sostener dignamente a sus familias. Esta desesperación empuja a decenas de hermanos a la peligrosa aventura de la migración... son conocidas las historias de abuso, violencia y muerte que padecen los migrantes que caen en las redes de tráfico de personas o de los cuerpos policíacos o paramilitares.

Las empresas transnacionales devoran sin piedad los recursos naturales del planeta; sin importarles la salud y el bienestar de esta y de las generaciones futuras.

La violencia institucional alcanza niveles insospechados en todos nuestros países: a las bandas de narcotraficantes, a las pandillas, a las maras, se unen los cuerpos policíacos corruptos, las guardias blancas, los grupos paramilitares y sectores del Ejército que, gozando de toda impunidad, provocan el terror y la muerte violenta entre la población civil.

La criminalización de la protesta social y la persecución a los líderes sociales, por un lado, y el acoso y persecución a las defensoras y defensores de los derechos humanos, por el otro, nos habla de un Estado represor que cambia el discurso, pero no los métodos de represión al pueblo organizado.

\section{La opción de monseñor Óscar Romero}

Monseñor Óscar Romero sabía bien de esta violencia. Cuando es nombrado arzobispo de San Salvador, el país ya vive una situación de represión y una clara persecución a los sectores más comprometidos de la sociedad y de la Iglesia.

Vivió el secuestro, la tortura, el exilio y el asesinato de varios de sus sacerdotes, religiosas, catequistas y laicos comprometidos.

Esto, como sabemos, abonó en su proceso personal de conversión, pero lo que más influyo en esta fue su clara opción por los pobres y por las víctimas que acudían a él buscando una palabra de consuelo y una liberación integral. Esa palabra quedó plasmada de manera contundente en sus homilías. Fueron palabras que hablaron la verdad, y por eso lo mataron; como mataron a Jesús por hablar con la verdad y por ser Él mismo la Verdad revelada por el Padre, como nos dice el Evangelio de San Juan.

Una verdad que, para hacernos mujeres y hombres verdaderamente libres, tiene que encarnarse y tiene que actualizarse en la realidad concreta de cada pueblo, de cada comunidad. 
Para monseñor Romero, como para muchos hermanos obispos, el Evangelio, el magisterio de la Iglesia, los documentos del Concilio Vaticano II, de Medellín y Puebla, fueron un espejo en el cual se reflejaban sus propios proyectos pastorales y su propia opción de "sentir con la Iglesia", esa Iglesia universal que es la Iglesia de los pobres, la Iglesia de Jesús. Pero los documentos no hacen Iglesia, la Iglesia se hace cuando ese Evangelio y ese magisterio echan raíces en la comunidad que los lee, que los reflexiona, que los pone en práctica.

Con humildad, monseñor reconocía sus límites y su condición humana; su diario espiritual nos habla de sus miedos y temores, pero también de una fe inquebrantable y de una coherencia entre su reflexión, su palabra y su acción cotidiana.

Esa coherencia le dio toda la autoridad moral para poder denunciar y exigir, desde el Evangelio, un verdadero Estado de derecho, que respetara la dignidad humana y que aplicara la justicia de manera expedita e imparcial.

Por eso es tan vigente su palabra, por eso hoy me atrevo a parafrasear lo dicho en una de sus homilías, para decirle a nuestros Gobiernos del siglo XXI que

de nada sirven las reformas si van teñidas con tanta sangre; de nada sirven los cambios de banderas, de partidos en el poder, de supuestas elecciones democráticas, si estos cambios solo sirven para perpetuar este sistema de muerte... de nada sirven Gobiernos emanados de la oposición, si no combaten a fondo esa violencia estructural que proviene de los mismos potentados económicos y de las mismas instancias gubernamentales y militares que se han perpetuado en el poder...

Ha llegado la hora de que la sociedad civil organizada reclame para sí el derecho a gobernar, el derecho a darse las autoridades que merece, el derecho a ejercer plenamente su soberanía, aplicando una justicia que no deje en la impunidad tantos crímenes cometidos en nombre de una supuesta democracia y de una aparente libertad. El derecho de los niños, de los jóvenes y de las mujeres a ser tomadas en cuenta en estas sociedades machistas, el derecho de la tierra y de la naturaleza a ser respetadas. El futuro está en nuestras manos, hermanas y hermanos, y no en las manos de políticos corruptos o de militares golpistas.

Así leyó monseñor Romero, en ese entonces y con toda claridad, "el testimonio subversivo de las Bienaventuranzas que le han dado vuelta a todo", y entendió que había que quitar la violencia desde sus bases, la violencia estructural, la injusticia social. Y, por tanto, es deber de la Iglesia "conocer los mecanismos que engendran la pobreza". La opción preferencial por los pobres es una invitación para la Iglesia como un todo, pero también para todo seguidor de Cristo. "El cristiano que no quiere vivir este compromiso de solidaridad con el pobre no es digno de llamarse cristiano", dijo, y añadía: "Los pobres 
han marcado, por eso, el verdadero caminar de la Iglesia. Una Iglesia que no se une a los pobres para denunciar, desde los pobres, las injusticias que con ellos se cometen no es verdadera Iglesia de Jesucristo" (homilía del 23 de septiembre de 1979).

Reconoció, en ello, su propio encargo como arzobispo: "Esta denuncia, creo un deber hacerla en mi condición de pastor del pueblo que sufre la injusticia. Me lo impone el Evangelio, por el que estoy dispuesto a enfrentar el proceso y la cárcel" (homilía del 14 de mayo de 1978).

\section{Despedida}

Hermanas y hermanos, esta eucaristía, las procesiones, peregrinaciones y marchas, los encuentros nacionales e internacionales, la unidad ecuménica de las iglesias, los congresos, los festivales, la participación de los niños y jóvenes de todas partes de El Salvador; los diversos eventos y conmemoraciones tenidas hoy mismo en muchos países de Europa, América y África negra, recordando la vida y la obra de monseñor Romero, nos hablan de la vigencia y de la fuerza de su testimonio.

Nos emocionan y nos provocan sus palabras, para enfrentar con valentía esta crisis de la que hemos hablado; nos animan, incluso, a enfrentar la posibilidad de la muerte, tal y como él la enfrentó:

Debo decirle que, como cristiano, no creo en la muerte sin Resurrección: si me matan, resucitaré en el pueblo salvadoreño...

Como pastor, estoy obligado, por mandato divino, a dar la vida por quienes amo, que son todos los salvadoreños, aun por aquellos que vayan a asesinarme. Si llegaran a cumplirse las amenazas, desde ya ofrezco a Dios mi sangre por la resurrección de El Salvador.

El martirio es una gracia de Dios que no creo merecer, pero si Dios acepta el sacrificio de mi vida, que mi sangre sea semilla de libertad y la señal de que la esperanza será pronto una realidad...

Dios lo premió con la palma del martirio y acogió con agrado su sacrificio colocándolo al lado de la cruz de Jesús. Y Dios, que cumple sus promesas, lo ha resucitado ya en las luchas y en el caminar del pueblo salvadoreño, del pueblo latinoamericano y del pueblo internacionalista solidario.

Por todo ello, no nos cabe duda del sentido profético que tuvo su vida, y del carácter martirial que tuvo su muerte. Por eso, junto al pueblo, junto a las víctimas y a los pobres a los que él sirvió, tampoco nos cabe duda de su santidad, que tarde o temprano será oficialmente declarada, no por sus méritos y por acciones humanas, como ya hemos dicho, sino por la acción misma del Espíritu. 
En él vemos que en América Latina se inició una nueva época en la que los cristianos, muriendo por la fe, dan su vida por la justicia. ;Esa fue la verdad de Romero, esa es la Verdad del Evangelio, esa es la Verdad que nos libera!

Que monseñor Romero, nuestro San Romero de América, junto a monseñor Proaño, junto a monseñor Gerardi, junto a don Sergio y Angelelli, siga iluminando en la Esperanza las causas de los pobres, de la justicia y del Reino de dignidad y de justicia para todos.

En el nombre del Padre, del Hijo y del Espíritu Santo, amén. 